\title{
Study on the Talent Cultivation Mode in Requirements of the Credit Management System
}

\author{
X.D. Yuan \\ Materials Science and Engineering Institute \\ Shandong Jianzhu University \\ Jinan, Shandong, China
}

\author{
G.L. Yuan \\ Jinan Engineering Quality and Work Safety Supervision \\ Station \\ Shandong Ji’nan, China
}

\author{
X.J. Yang \\ Shandong Product Quality Inspection Research Institute \\ Ji'nan, China \\ Shandong Key Laboratory for Testing Technology of Material Chemical Safety \\ Ji'nan, China
}

\begin{abstract}
Training system of the engineering and technical personnel was implemented by School of materials science and engineering, Shandong Jianzhu University in requirements of the credit management system, and the cultivation quality for undergraduates were improved. The influence of the1234 training system of the engineering and technical personnel on the cultivation quality for undergraduates was studied taking the study on the friction and wear properties of Cr-Rare earth-Boronized layer as an example, and reasons were also analyzed.
\end{abstract}

Keywords-credit system; 1234 training system; Cr-rare earth-boronizing; steel 45

\section{INTRODUCTION}

The credit system is a kind of the elective system, in which the study quantity of students was calculated by credits, and students can apply for graduate until they obtain certain credits. The learning of students under credit system is elastic. They learn various courses and receive course credits. Students can apply for graduate when they obtain the lowest credits which satisfied the requirements of the school. Studies, including the teaching reform of school and professional, the personnel training mode, school enterprise cooperation and the reform of teaching practice were carried out by some colleges and universities in the "credit system" requirements [1-6].The university tried he student credit system management and formulated educational objectives since 2012. Researches on the demand for materials engineering technical personnel were carried out combing the characteristics of the material science itself by Shandong Jianzhu University. 1234 Training system of the engineering and technical personnel was implemented and the experiment technical ability of students was improved.

\section{TRAINING SYSTEM}

1234 Training system of the engineering and technical personnel is a training system which focuses on integrating resource superiority of teaching tutorial (young teachers) and ideological mentor (counselor), making full use of advantages of three-dimensional platform among the laboratory, businesses and industries, and improving engineering practical ability of students gradually. In the first year, students make efforts to learn theoretical knowledge and consolidate the foundation. In the second year students experience "Internship", understand the needs of enterprises. In the third year students participate or declare laboratory research projects, participate in the international conference and all kinds of associations of industry, innovate in thinking, and researches with great concentration. In the forth year, students carry out the work of graduation design combining engineering technical problems of enterprises, solve problems independently, and realize the independent innovation. Implementation mode is shown in Figure 1.

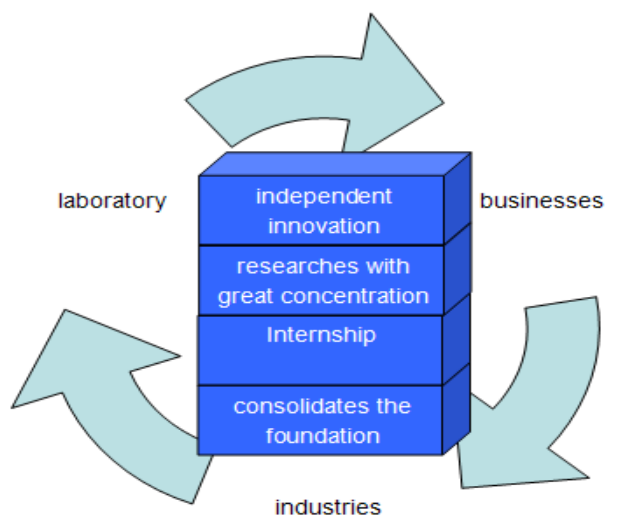

FIGURE I. 1234 TRAINING SYSTEM OF THE ENGINEERING AND TECHNICAL PERSONNEL.

\section{EXPERIMENTS}

\section{A. Objective}

Boronizing is the technical process to add boron atoms into the surface of materials and hence to form borides eventually. This process happens due to the chemical or electrochemical reactions by heating the target materials within boracic environment. This advanced technique can make boron atoms disperse into the target materials via chemical reaction to form 
the boride layer with extreme hardness, excellent wear resistance and stronger corrosion resistance [7-9].

\section{B. Experimental Details}

\section{1) Materials}

Materials mainly used in this study were steel 45 . Parts of samples were quenched in water at $850^{\circ} \mathrm{C}$ and tempered at $200^{\circ} \mathrm{C}$. Parts of samples were Cr-Rare earth-boronized in a penetrating tank at 650 for $6 \mathrm{~h}$.

\section{2) Experimental Approach}

The friction and wear behavior of samples was performed on a wear tester. All samples were slid against a steel T12. All sliding tests were carried out at an angular velocity of 200 $\mathrm{r} / \mathrm{min}$, loads of $1500 \mathrm{~N}$, and the duration was $5 \mathrm{~min}$. five samples were tested at each condition. The friction coefficient and weight loss were the average values of these tests. The friction coefficient of samples was determined by measuring the friction torque, while the friction torque was detected by a torque measuring system. The sliding distance was calculated by diameter and angular velocity. The weight loss was calculated by the mass of samples before and after each test to an accuracy of $0.01 \mathrm{mg}$.

\section{Results and Discussion}

Variations of weight loss with the sliding distance were shown in Figure 2. It can be seen from Figure 2 that the weight loss of quenched samples was lower than that of Cr-Rare earth-Boronized samples during the early period of friction. It was because of that the surface of Cr-Rare earth-Boronized samples was looser with a lot of holes. And the weight loss of quenched samples was higher than that of Cr-Rare earth-Boronized samples with a further increase of sliding distance.

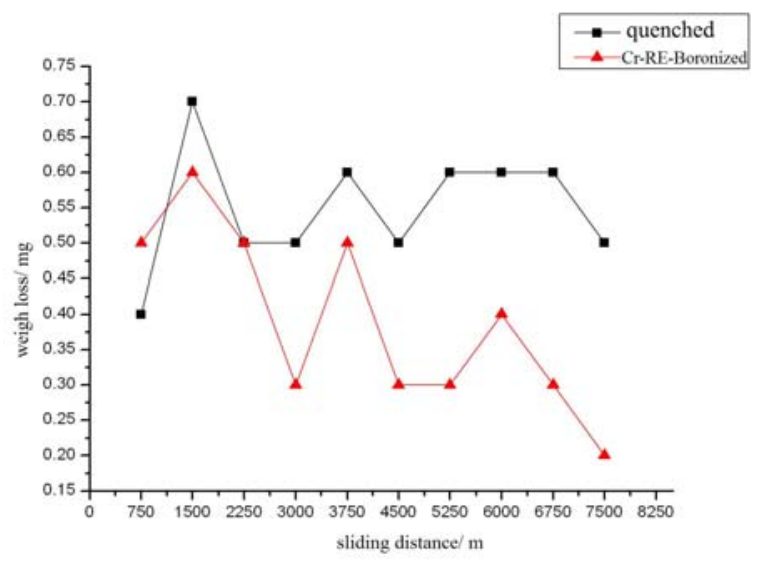

FIGURE II. VARIATIONS OF WEIGHT LOSS WITH THE SLIDING DISTANCE.

Variations of friction coefficient with the sliding distance were shown in Figure 3. It can be seen from Figure 3 that the friction coefficient of quenched samples was higher than that of Cr-Rare earth-Boronized samples. It was in accordance with the results of Figure 2. It was probably because of that the vacancies in phase Fe2Bwere occupied by chrome and rare earth atoms, leading to the increase of density. Meanwhile, the compounds formed by the rare earth atoms and the impurities in grain boundaries resulting in the decrease of brittleness of boride layer. And then the origination and propagation of cracks were inhibited.

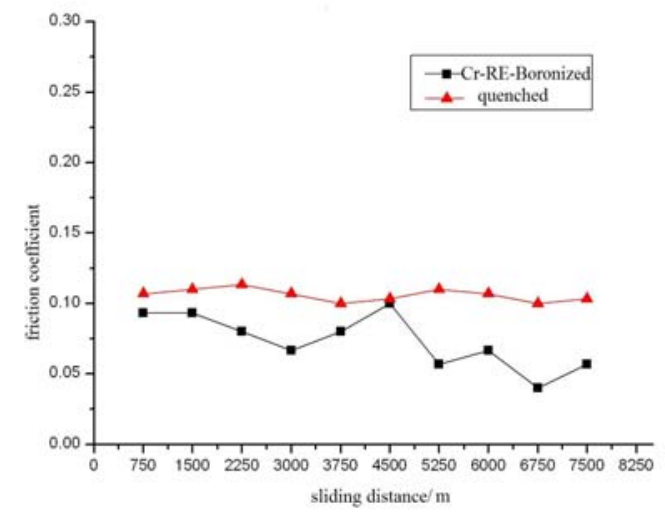

FIGURE III. VARIATIONS OF FRICTION COEFFICIENT WITH SLIDING DISTANCE.

The wear resistance can be represented by the reciprocal of weightlessness. The weight loss of Cr-Rare earth-Boronized samples and quenched samples are $3.9 \mathrm{mg}$, and $5.5 \mathrm{mg}$. And the wear resistance of Cr-Rare earth-Boronized samples is 0.256 which is superior to that of quenched samples 0.182 .

The relative wear resistance is represented by the weight loss of quenched samples divided by the weight loss of Cr-Rare earth-Boronized samples, which is 1.41 . It can be concluded that the wear resistance of Cr-Rare earth-Boronized samples is 1.4 times higher than that of quenched samples.

\section{CONCLUSIONS}

1234 Training system of the engineering and technical personnel was implemented by the school of materials science and engineering of Shandong Jianzhu University since the implement of the credit system. The cultivation quality of undergraduates was improved.

\section{ACKNOWLEDGEMENT}

Sponsored by the Research Fund for the College science and technology plan of Shandong Province. (Project No. J12LA11).

\section{REFERENCE}

[1] $\mathrm{Xu} \mathrm{Z} \mathrm{B,} \mathrm{Xu} \mathrm{J} \mathrm{H.} \mathrm{on} \mathrm{the} \mathrm{teaching} \mathrm{management} \mathrm{in} \mathrm{the} \mathrm{full} \mathrm{credit} \mathrm{system}$ $[\mathrm{J}]$. journal of hebel normal univer sity/educational science edition, 2009,11(2):90-93.

[2] Yan G F, Zai X J. The credit system of colleges and universities charge [J]. china academic journal electronic publishing house, 2007(8):58-60.

[3] Feng X D. to practice the credit system: a profound transform in teaching and opinion $[\mathrm{J}]$. systemjournal of higher education, 2003,24(6):59-63.

[4] Lv X L, Dai J F, Hu M G. open experimental teaching based on credit system [J]. research and exploration in laboratory, 2012,31(8):121-124.

[5] Zhou Q M. analysis on supervision of teaching quality under credit system [J]. systemjournal of higher education, 2003,24(5):80-82.

[6] Luo Q L, Chen Y L. The measure of accumulated-points in the credit system [J]. Application of statistics and management, 2004,24(6):48-53.

[7] P.X.Yan,Y.C.Su.Metal surface modification by B-C-nitriding in a 
two-temperature-stage process. Materials Chemistry and Physics 1995, 39: 304-308.

[8] M. Keddam. Computer simulation of monolayer growth kinetics of $\mathrm{Fe}_{2} \mathrm{~B}$ phase during the paste-boriding process: Influence of the paste thickness. Applied Surface Science 2006, 253:757-761.

[9] M.A. Béjar , R. Henríquez. Surface hardening of steel by plasma-electrolysis boronizing. Materials and Design 2009, 30: 1726-1728. 